
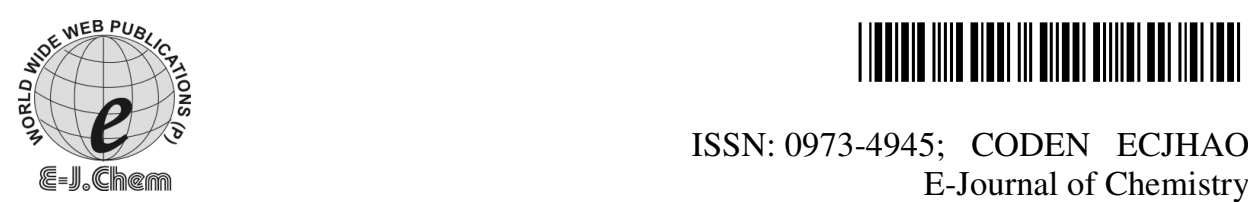

ISSN: 0973-4945; CODEN ECJHAO

E-Journal of Chemistry

http://www.e-journals.net 2009, 6(3), 713-724

\title{
Sorptive Response Profile of Chitosan Coated Silica in the Defluoridation of Aqueous Solution
}

\author{
Y. VIJAYA and A. KRISHNAIAH* \\ Biopolymers and Thermophysical Laboratories, \\ Department of Chemistry, \\ Sri Venkateswara University, Tirupati-517 502, A.P., India. \\ abburikrishnaiah@gmail.com
}

Received 16 October 2008; Accepted 12 December 2008

\begin{abstract}
As excess of fluoride (>1.5 $\mathrm{mg} / \mathrm{L}$ ) in drinking water is harmful to the human health, various treatment technologies for removing fluoride from groundwater and aqueous medium have been investigated in the past. Present investigation aims to develop chitosan coated silica (CCS) and to investigate the removal of fluoride by CCS through adsorption. Fourier transform infrared spectroscopy (FTIR), Scanning electron microscopy (SEM), Thermo gravimetric analysis (TGA), X-ray diffraction (XRD) were used for the characterization of the sorbent. The surface morphology of the CCS was observed using SEM. Series of batch adsorption experiments were carried out to assess parameters that influence the adsorption process. The factors investigated include the influence of $\mathrm{pH}$, contact time, adsorbent dose and initial fluoride concentration. The studies revealed there is an enhanced fluoride sorption on CCS. The sorption data obtained at optimized conditions were subjected to Langmuir and Freundlich isotherms. The monolayer sorption capacity, $\mathrm{Q}^{\circ}(44.4 \mathrm{mg} / \mathrm{g})$ and binding energy $b(0.010 \mathrm{~L} / \mathrm{mg})$ have been estimated using Langmuir isotherm. The kinetic studies indicate that the sorption of fluoride on CCS follows Pseudo second-order kinetics.
\end{abstract}

Keywords: Defluoridation, CCS, Adsorption, Isotherms, Kinetics, FTIR, SEM, TGA, XRD.

\section{Introduction}

Fluoride enters into water due to both natural processes and human activity. Since fluoride is present in several minerals, it can be leached out by rainwater thereby allowing it to contaminate ground and surface water. On the other hand several fluoride compounds have industrial applications and these also contribute to fluoride pollution. Fluoride is frequently encountered in minerals and in geochemical deposits. Because of the erosion and weathering 
of fluoride-bearing minerals it becomes a surface species. On the other hand, fluorine compounds are industrially important and are extensively used in semiconductors, fertilizers, aluminium industries, and nuclear applications. Toxic wastes containing fluorine/fluoride are generated in all industries using fluorine or its compounds as raw materials. Prominent among these is the aluminium smelter where fluoride gas is released into the atmosphere. Fluoride is an essential constituent for both humans and animals. Within permissible limits of $0.5-1.0 \mathrm{mg} / \mathrm{L}$, is beneficial for the production and maintenance of healthy bones and teeth, while excessive intake of fluoride causes dental or skeletal fluorosis which is a chronic disease manifested by mottling of teeth in mild cases, softening of bones and neurological damage in severe cases ${ }^{1-4}$. Many countries have regions where the water contains more than $1.5 \mathrm{mg} / \mathrm{L}$ of fluoride due to its natural presence in the earth's crust, or discharge by agricultural and industrial activities, such as steel, aluminium, glass, electroplating ${ }^{5-7}$.

The World Health Organization has set a guidance value of $1.5 \mathrm{mg} / \mathrm{L}$ for fluoride in drinking water ${ }^{8}$. Adsorption has been considered as the most efficient and applicable technology for fluoride removal from drinking water compared to other technologies like reverse osmosis, nanofiltration, electro dialysis and Donnan dialysis ${ }^{9-12}$. Activated alumina $^{13}$, bone char $^{14}$, activated carbon ${ }^{15}$ and some other low-cost materials ${ }^{16,17}$ have been used as fluoride adsorbents. Among these adsorbents, activated alumina is the most widely used because it is readily available and inexpensive. However, frequent regeneration with aluminum sulfate is needed because of its low adsorption capacity at neutral $\mathrm{pH}^{18}$, which results in increased difficulty for operation and increased dissolved aluminium in treated water.

The primary objective of this research was to study the biosorption of fluoride from aqueous environment by chitosan coated silica under equilibrium and column flow conditions. The secondary objective was to investigate the effect of $\mathrm{pH}$, contact time, concentration of fluoride and amount of biomass on the extent of adsorption. The tertiary objective included the fitting of the experimental data to Freundlich and Langmuir adsorption isotherms and Lagergren first order, pseudo second order and Weber-Morris intraparticle diffusion kinetic models.

\section{Experimental}

Chitosan and silica, used for preparation of chitosan coated silica, were obtained from Loba Chemie, Mumbai, India. Analytical reagent grade sodium fluoride, hydrochloric acid and sodium hydroxide from S.D. Fine Chemicals were used as source of fluoride and for the $\mathrm{pH}$ adjustment. Total ionic strength adjustment buffer (TISAB), used to eliminate the interference effect of complexing ions from fluoride solution, was obtained from Thermo Electron Corporation, USA. Doubly distilled water was used in all experimental work.

The stock solution of fluoride was prepared by dissolving $2.21 \mathrm{~g}$ of sodium fluoride in $1000 \mathrm{~mL}$ of double distilled water such that each $\mathrm{mL}$ of the solution contains $1 \mathrm{mg}$ of fluoride. The exact concentration of fluoride solution was calculated on mass basis and expressed in terms of $\mathrm{mg} / \mathrm{L}$. The required lower concentrations were prepared by dilution of the stock solution. All precautions were taken to minimize the loss due to evaporation during the preparation of solutions and subsequent measurements. The solutions were prepared fresh for each experiment as the concentration of the solution may change on long standing. 


\section{Preparation of chitosan coated silica}

Chitosan gel was prepared by adding $4 \mathrm{~g}$ of chitosan to $100 \mathrm{~mL}$ of $2 \%$ acetic acid and stirring for about $4 \mathrm{~h}$. Ten grams of silica, washed with $2 \%$ acetic acid solution, were added to $100 \mathrm{~mL}$ of $4 \%$ chitosan gel while stirring with a magnetic stirrer for $4 \mathrm{~h}$. This process leads to the formation of silica / chitosan suspension. This suspension was dropped into $500 \mathrm{~mL}$ of $0.1 \mathrm{M}$ $\mathrm{NaOH}$ solution while stirring to neutralize excess acid. The suspension was converted into beads. The beads were washed with double distilled water until the washings were neutral.

\section{Batch sorption experiments}

In order to explore the effect of influencing factors, such as $\mathrm{pH}$, contact time, quantity of adsorbent and the initial concentration of fluoride solution, a series of batch experiments were conducted. The stock solutions were diluted to required concentrations $(10,15$ and 20 $\mathrm{mg} / \mathrm{L}$ ). Batch adsorption experiments were performed by agitating specified amount of adsorbent in $100 \mathrm{~mL}$ of fluoride solution of desired concentrations at varying $\mathrm{pH}$ in $125 \mathrm{~mL}$ stopper bottles. The $\mathrm{pH}$ of the suspension was adjusted with $0.01 \mathrm{M} \mathrm{HCl}$ and $0.01 \mathrm{M} \mathrm{NaOH}$. The reaction mixture was agitated at $200 \mathrm{rpm}$ for a known period of time at room temperature in a mechanical shaker. After equilibrium, the aqueous-phase concentration of fluoride was analyzed with fluoride ion selective electrode (I.S.E). Adsorption of fluoride on the glassware was found to be negligible and was determined by running blank experiments. The percentage removal of fluoride was obtained using the equation.

$$
\text { \%removal }=\frac{C_{i}-C_{e}}{C_{i}} X 100
$$

The amount adsorbed per unit mass of adsorbent at equilibrium $q_{e}(\mathrm{mg} / \mathrm{g})$ was obtained using the equation.

$$
Q_{e}=\left(\frac{C_{i}-C_{e}}{m}\right) v
$$

Where, $C_{i}$ and $C_{e}$ denoted the initial and equilibrium fluoride ion concentrations $(\mathrm{mg} / \mathrm{L})$ respectively. ' $v$ ' was the volume of the solution in liters, and ' $m$ ' was the mass of the adsorbent used $(\mathrm{g})$.

\section{Column adsorption experiments}

Column studies were carried out in a column made of Pyrex glass of $1.5 \mathrm{~cm}$ internal diameter and $15 \mathrm{~cm}$ length. The column was filled with of dried CCS by tapping so that maximum amount of adsorbent was packed without gaps. The influent aqueous fluoride solution containing known concentration was filled in the reservoir of large cross sectional area so that the change in the height of the liquid level was negligible during the experiment. Due to the negligible change in the height of the liquid level the flow rate remains constant. The influent solution was allowed to pass through the bed at constant flow rate of $2 \mathrm{~mL} / \mathrm{min}$, in down flow manner with the help of a fine metering valve. All the experiments were carried out at room temperature. The effluent solution was collected at different time intervals and the concentration of the fluoride in the effluent solution was monitored by ion selective electrode using Orion Ion 4 Star Series Meter (Thermo Electron Corporation, USA).

The adsorption capacity of fluoride was obtained in column at different cycles using the equation.

$$
q_{e}=\left(\frac{C_{i}-C_{e}}{m}\right) \cdot b v
$$


where, $C_{i}$ and $C_{e}$ denote the initial and equilibrium (at breakthrough) fluoride ion concentration $(\mathrm{mg} / \mathrm{L})$ respectively. $b v$ was the breakthrough volume of the $\mathrm{NaOH}$ solution in liters, and $m$ was the mass of the adsorbent used (g).

\section{Column desorption studies}

Desorption (regeneration) studies are very important since the success of adsorption process depends on the regeneration of adsorbent. There are several methods for the desorption of the adsorbate from the loaded adsorbents. In the present study the elution method with solvent is used to remove the adsorbed fluoride from CCS.

After the column was exhausted, the column was drained off the remaining aqueous solution by pumping air. Desorption of solute from loaded adsorbent CCS was carried out by solvent elution method using $0.1 \mathrm{M} \mathrm{NaOH}$ as eluent. The $\mathrm{NaOH}$ solution was pumped into the column maintained at constant temperature at a fixed flow rate $(1 \mathrm{~mL} / \mathrm{min})$. From the start of the experiment effluent samples at different intervals were collected at the bottom of the column for analysis. After the regeneration, the adsorbent column was washed with distilled water to remove $\mathrm{NaOH}$ from the column before the influent fluoride solution was reintroduced for the subsequent adsorption-desorption cycles. Adsorption-desorption cycles were performed thrice using the same bed to check the sustainability of the bed for repeated use.

\section{Determination of fluoride concentration}

The concentration of fluoride in the solutions was determined using a fluoride ion selective electrode $^{19}$, which measures concentrations from $10^{-6} \mathrm{M}$ to saturated solutions. TISAB-III (Total Ionic Strength Adjustment Buffer) was added to the solutions to reduce the variation in the ionic strength in the samples. This buffer contains a chelate, which forms complexes with other ions, such as iron, aluminium that could interfere in the determinations. A calibration curve was obtained using $\mathrm{NaF}$ standard solutions with different fluoride concentrations from 1 to $10 \mathrm{mg} / \mathrm{L}$. The results were plotted as fluoride concentration $(\mathrm{mg} / \mathrm{L}$ ) versus potential $(\mathrm{mV})$.

\section{Results and Discussion}

\section{Characterization}

In order to understand the nature of fluoride sorption on CCS biosorbent FTIR (Fourier Transform Infrared Spectroscopy), SEM (Scanning Electron Microscopy), TGA (Thermo Gravimetric Analysis) and XRD (X-Ray Diffraction) studies were performed. FTIR spectra of CCS before and after fluoride sorption are presented in Figure 1a and b, respectively. CCS shows a peak (Figure 1(a)) at the wave number $797 \mathrm{~cm}^{-1}$ (C-H group out of plane). A broad peak at around $1092 \mathrm{~cm}^{-1}$ may be due to the merging of peaks relating to $\mathrm{Si}-\mathrm{O}-\mathrm{Si}, \mathrm{Si}$ $\mathrm{O}-\mathrm{H}, \mathrm{C}-\mathrm{O}$ groups. Another broad peak around $3439 \mathrm{~cm}^{-1}$ is attributed to $-\mathrm{NH}$ and $\mathrm{O}-\mathrm{H}$ stretching vibrations. Significant changes in the FTIR spectra after the fluoride sorption (Figure 1(b)) were found to be at the wave numbers of 3412, 1677, 1649, 1541, 1454 and $1089 \mathrm{~cm}^{-1}$. Display of strong broad O-H stretch carboxylic bands in the regions $3412 \mathrm{~cm}^{-1}$ and carboxylic/phenolic stretching bands in the regions of $2923 \mathrm{~cm}^{-1}$ were observed. The bands appeared in the region $1649 \mathrm{~cm}^{-1}$ might be attributed to $>\mathrm{C}=\mathrm{N},>\mathrm{C}=\mathrm{C}$ and $\mathrm{C}=\mathrm{O}$ stretch. The bands appeared in the region of 1540 and $1400 \mathrm{~cm}^{-1}$ might be attributed to the presence of $\mathrm{O}-\mathrm{H}$ bonds. The band appearing in the region $1010 \mathrm{~cm}^{-1}$ indicated the presence of -C-F stretch. FTIR results indicated that the hydroxyl and amine groups are responsible for fluoride sorption. 


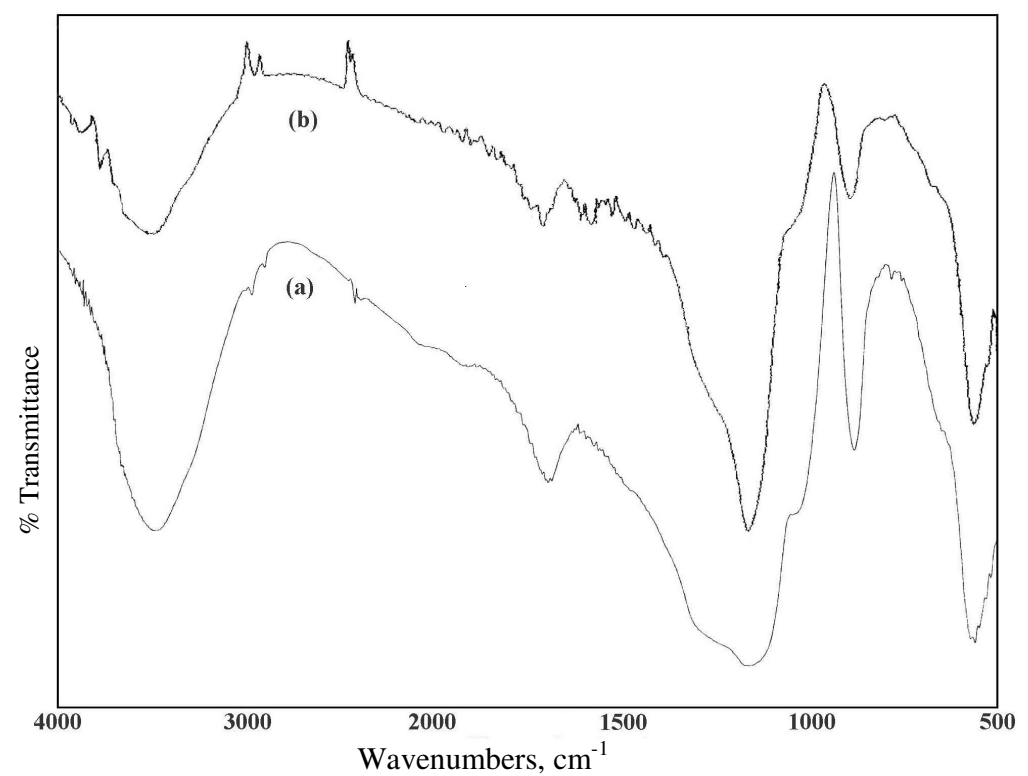

Figure 1. FTIR spectra of (a) CCS (b) CCS with fluoride.

The SEM images of the surface of CCS before and after adsorption, shown in Figure 2(a) and (b) display a rough structure on surface with a large surface area of CCS. An examination of the SEM micrographs indicated the presence of many pores and also some cracks on the surface of the CCS biosorbent. CCS was somewhat swollen during the contact with fluoride solution. The thermogram (Figure 3) of CCS showed a broad transition with a relatively less weight loss. The weight loss was about $3 \%$ around $150{ }^{\circ} \mathrm{C}$ and about $6 \%$ at $360{ }^{\circ} \mathrm{C}$. Thermogram of CCS indicates that about $8 \%$ of chitos an is coated on silica. From the TGA analysis of the biosorbent, it may be concluded that the biosorbent could be used even at higher temperatures in water treatment. The respective XRD patterns of CCS samples before and after fluoride sorption are presented in Figure 4(a) and (b). The results revealed that there is no major change in the crystal structure after fluoride adsorption at this low concentration level. Similar results on XRD patterns on fluoride adsorption were reported by Diaz-Nava et $a l^{20}$ while studying the defluoridation capacity of zeolite.
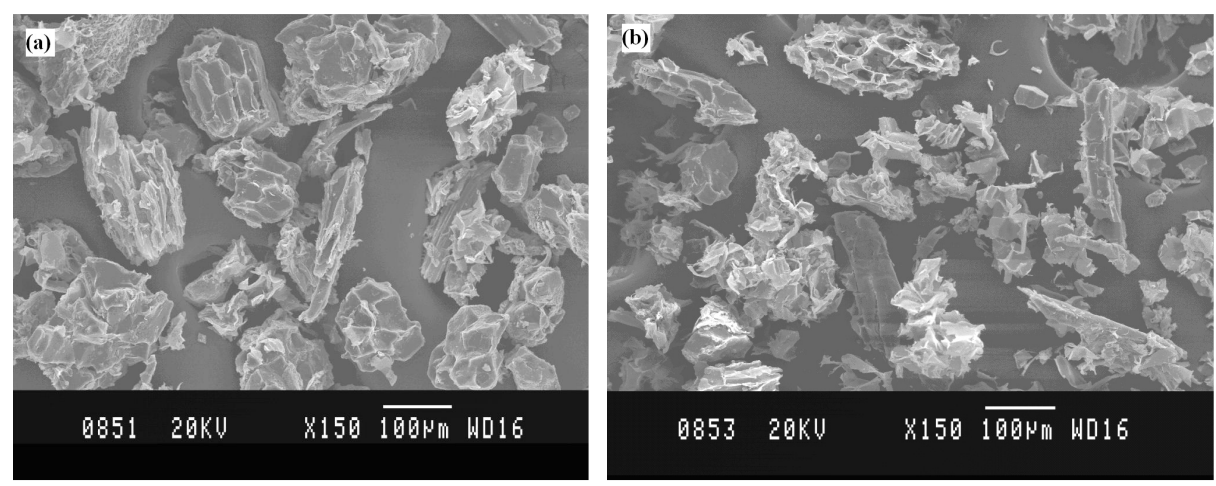

Figure 2. SEM images of (a) CCS (b) CCS with fluoride. 


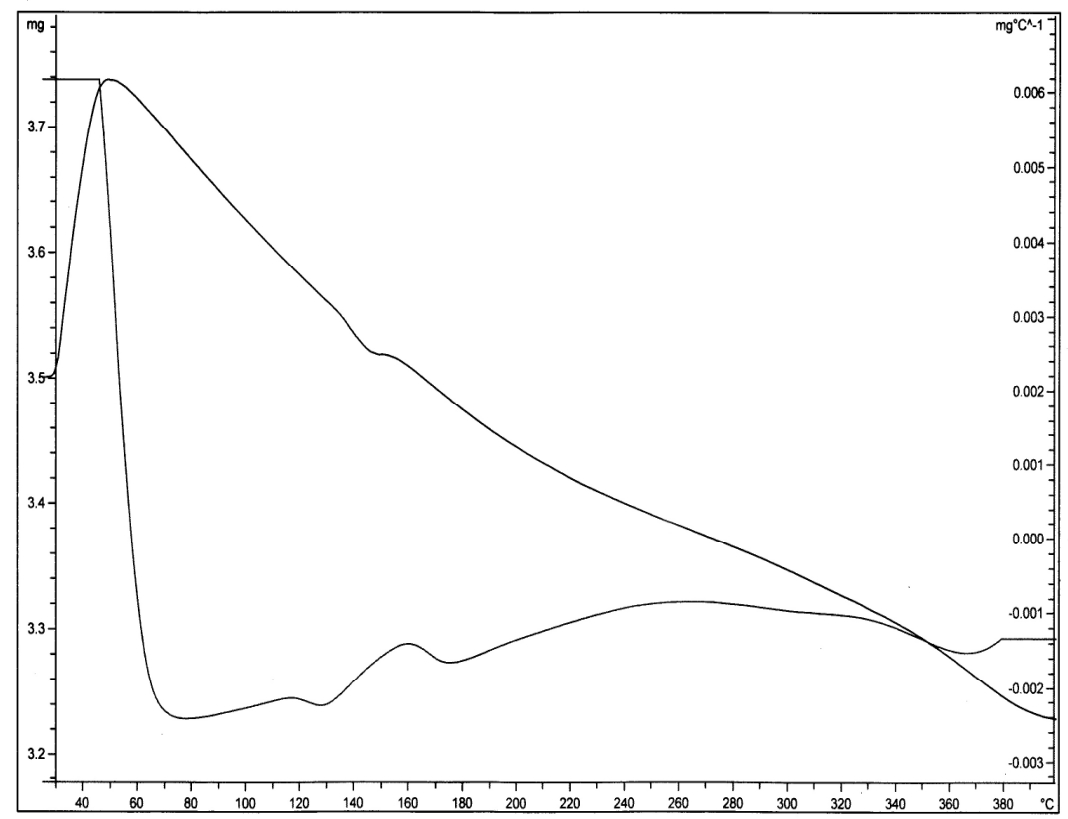

Figure 3. TGA image of CCS.

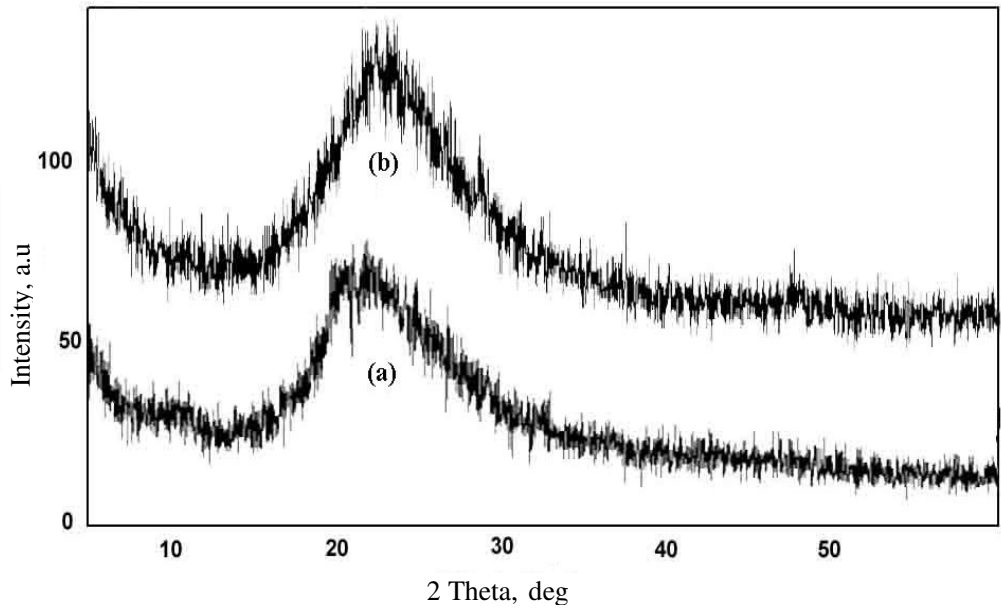

Figure 4. XRD images of (a) CCS (b) CCS with fluoride.

\section{Influence of $\mathrm{PH}$}

The $\mathrm{pH}$ of the aqueous solution plays an important role which controls the adsorption at the water adsorbent interface ${ }^{21}$. Therefore the adsorption of fluoride on the CCS was examined at various $\mathrm{pH}$ values ranging from 1-8 with an initial fluoride concentration of $10 \mathrm{mg} / \mathrm{L}$ at room temperature. The results were presented in Figure 5. The $\mathrm{pH}$ of the working solution is controlled by adding sufficient $\mathrm{HCl} / \mathrm{NaOH}$ solution. Removal of fluoride increases with increase in $\mathrm{pH}$ up to 4.0 and decreases there on. The maximum defluoridation capacity is $82 \%$ at $\mathrm{pH}$ 4.0. Similar trend was observed by Karthikeyan et $a l^{22}$ with adsorption of fluoride ion on activated alumina. 


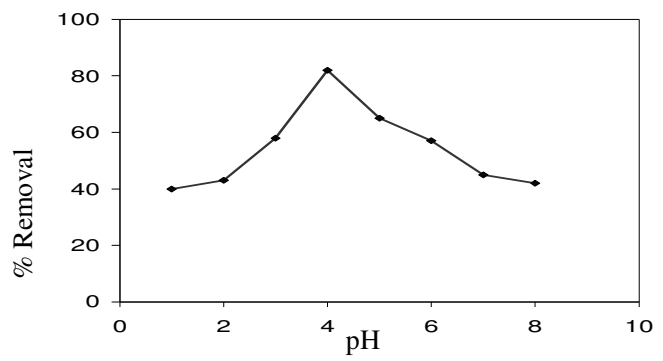

Figure 5. Influence of $\mathrm{P}^{\mathrm{H}}$ on percent removal of fluoride on CCS.

\section{Influence of initial concentration}

The effect of initial fluoride concentration on the percentage removal of fluoride was studied at different initial fluoride concentrations by keeping all other parameters such as adsorbent dose $0.5 \mathrm{~g} / 100 \mathrm{~mL}, \mathrm{pH}$, shaking speed $200 \mathrm{rpm}$ and contact time $180 \mathrm{~min}$ constant. It was noticed that with increase in initial fluoride concentration, the percentage removal of fluoride decreases. At higher adsorbate concentration, the binding capacity of the adsorbent approaches saturation resulting in decrease in overall percent removal.

\section{Equilibrium modeling}

Analysis of the equilibrium data is important to develop an equation which accurately represent the adsorption process and which could be used for design purposes. Langmuir ${ }^{23}$ and Freundlich ${ }^{24}$ adsorption isotherms were used to fit the experimental data. To obtain the isotherms, initial concentrations of fluoride were varied from 10 to $20 \mathrm{mg} / \mathrm{L}$ while keeping the weight of CCS, pH and contact time constant. The Langmuir isotherm assumes monolayer adsorption where as the Freundlich isotherm is an empirical model that is based on sorption on heterogeneous surface. The parameters of Langmuir and Freundlich adsorption isotherms, evaluated from the linear plots, are presented in Table 1 along with the correlation coefficient. Both the models are capable of representing the data adequately. The magnitude of the Freundlich constants, $\mathrm{k}_{\mathrm{F}}$ and $\mathrm{n}$ indicate that the uptake of fluoride from aqueous solutions by the CCS is feasible. Langmuir constant, $\mathrm{Q}^{\circ}$, represents the maximum monolayer adsorption capacity $(44.4 \mathrm{mg} / \mathrm{g})$ of the biosorbent. Adsorption capacities of chitosan and modified chitosan sorbents, collected from the literature, are included in Table 3 along with the values corresponding to CCS for comparison. The sorbent developed in the present study exhibits higher adsorption capacity compared to chitosan in its natural and modified forms ${ }^{25-27}$.

Table 1. Langmuir and Freundlich constants for adsorption of fluoride on CCS.

\begin{tabular}{ccccccc}
\hline \multicolumn{3}{c}{ Langmuir constants } & \multicolumn{4}{c}{ Freundlich constants } \\
\hline $\mathrm{Q}^{\mathrm{o}}, \mathrm{mg} / \mathrm{g}$ & $\mathrm{b}, \mathrm{L} / \mathrm{mg}$ & $\mathrm{R}^{2}$ & $\mathrm{k}_{\mathrm{F}}$ & $1 / \mathrm{n}$ & $\mathrm{n}$ & $\mathrm{R}^{2}$ \\
44.4 & 0.010 & 0.994 & 0.420 & 0.972 & 1.029 & 0.997
\end{tabular}

Table 2. Maximum adsorption capacity $(\mathrm{mg} / \mathrm{g})$ of different chitosan based adsorbents for fluoride.

\begin{tabular}{cccc}
\hline Adsorbent & $\begin{array}{c}\text { Maximum adsorption } \\
\text { capacity, mg/g }\end{array}$ & $\mathrm{pH}$ & References \\
\hline Magnetic chitosan particle & 22.49 & 7 & 25 \\
Chitin & 8.85 & 7 & 26 \\
Chitosan & $\mathrm{I} .08$ & 7 & 26 \\
Lanthanum modified chitosan & 84.2 & 6.7 & 26 \\
Chitosan & 1.39 & 6 & 27 \\
Chitosan coated silica & 44.4 & 4 & Present work \\
\hline
\end{tabular}


Table 3. Rate constants of kinetic models for the adsorption of fluoride on CCS.

\begin{tabular}{ccccccc}
\hline \multirow{2}{*}{$\begin{array}{c}\text { Concentration of } \\
\text { luoride solution, mg/g }\end{array}$} & \multicolumn{3}{c}{ First-order model } & \multicolumn{5}{c}{ Second-order model } \\
\cline { 2 - 7 } & $\mathrm{k}_{1}$ & $\mathrm{R}^{2}$ & $\begin{array}{c}\mathrm{Q}_{\mathrm{e}} \exp , \\
\mathrm{mg} / \mathrm{g}\end{array}$ & $\begin{array}{c}\mathrm{Q}_{\mathrm{e}} \mathrm{cal}, \\
\mathrm{mg} / \mathrm{g}\end{array}$ & $\mathrm{k}_{2}$ & $\mathrm{R}^{2}$ \\
\hline 10 & 0.029 & 0.993 & 1.7 & 1.9 & 0.039 & 0.998 \\
15 & 0.025 & 0.995 & 2.5 & 2.6 & 0.032 & 0.998 \\
20 & 0.022 & 0.981 & 3.4 & 3.7 & 0.032 & 0.998 \\
\hline
\end{tabular}

\section{Influence of contact time}

The effect of contact time on the extent of adsorption of fluoride at different concentrations is shown in Figure 6. The extent of adsorption increases with time and attained equilibrium for all the concentrations of fluoride studied $(10,15$ and $20 \mathrm{mg} / \mathrm{L}$ ) at $90 \mathrm{~min}$. After this equilibrium period, the amount of fluoride adsorbed did not change significantly with time. The amount of fluoride adsorbed versus time curves are smooth and continuous. The changes in the rate of removal might be due to the fact that initially all adsorbent sites were vacant and the solute concentration gradient was high. Later, the fluoride uptake rate by adsorbent had decreased significantly, due to the decrease in number of adsorption sites. Decreased removal rate, particularly, towards the end of experiment, indicates the possible monolayer of fluoride ions on the outer surface, pores of both the adsorbents and pore diffusion onto inner surface of adsorbent particles through the film due to continuous shaking maintained during the experiment.

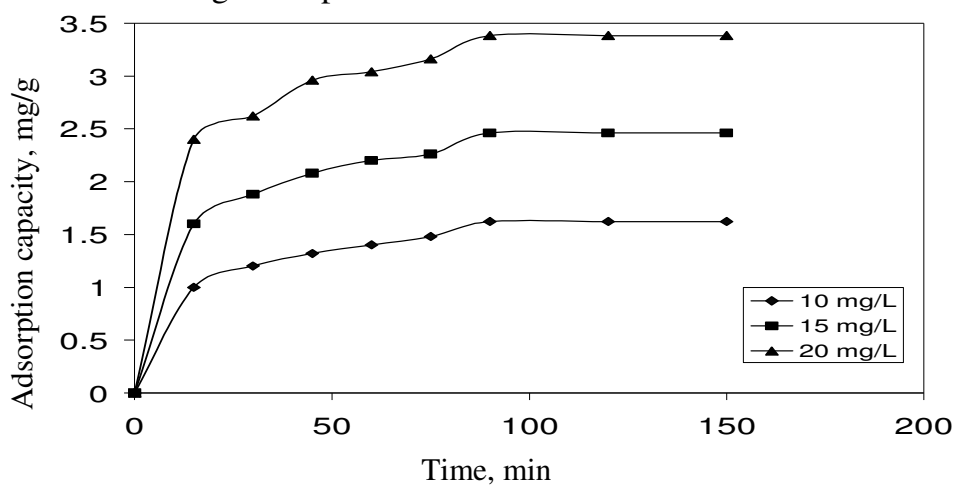

Figure 6. Influence of time on biosorption of fluoride on CCS.

\section{Kinetic studies}

In order to investigate the mechanism of sorption, the rate constants of sorption process were determined by using Lagergren first order ${ }^{28,29}$ and a pseudo-second order ${ }^{30}$ kinetic models. The values of the first and second order rate constants are included in Table 3. In many cases the first order equation of Legergren does not fit well to the whole range of contact time and is generally applicable over the initial stage of the adsorption process ${ }^{31}$. The second order kinetic model assumes that the rate limiting step may be chemical adsorption ${ }^{32}$. In many cases, the adsorption data could be well correlated by second order rate equation over the entire period of contact time ${ }^{33}$. The Legergren first-order and pseudo second-order kinetic plots for fluoride adsorption are given in Figures 7 and 8 . The results of the present study indicate that the adsorption of fluoride on CCS follows second-order kinetics. It was found that the correlation coefficient $\mathrm{R}^{2}$ values for this model was near to unity as compared to the $\mathrm{R}^{2}$ values as obtained in the first order kinetics. 


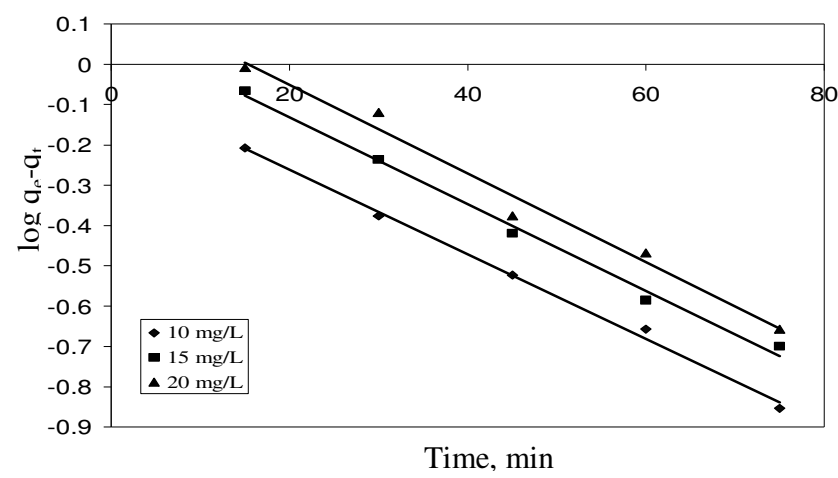

Figure 7. Legergren first-order kinetic plots for CCS.

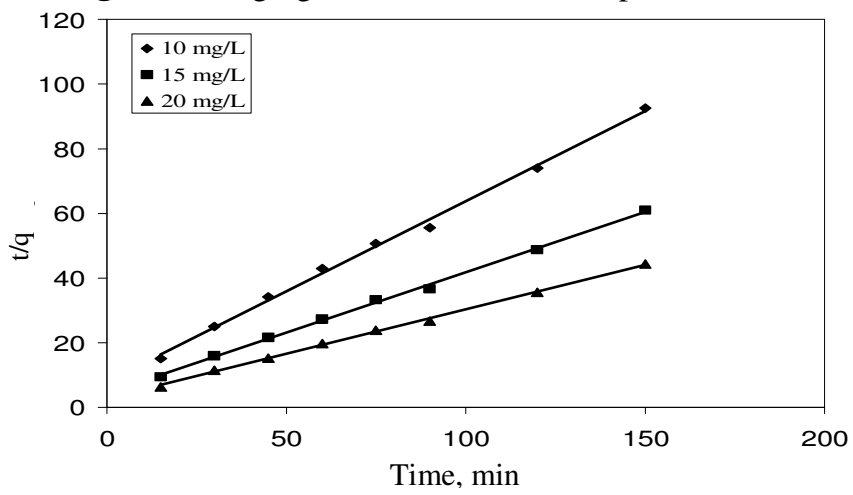

Figure 8. Pseudo second-order kinetic plots for CCS.

The results were also analyzed in terms intraparticle diffusion model to investigate whether the intraparticle diffusion was the rate controlling step in adsorption of fluoride on CCS. The model proposed by Weber and Morris ${ }^{34}$ can be written as, $q_{t}=K_{i d} t^{1 / 2}$, where $K_{i d}$ $\left(\mathrm{mg} / \mathrm{g} \mathrm{min}^{-1 / 2}\right)$ is the rate constant of intraparticle diffusion. The Weber-Morris plot for adsorption of fluoride is given in Figure 9. If the intraparticle diffusion is the sole rate determining step, the plots of $q_{t}$ versus $t^{1 / 2}$ should be linear and pass through the origin ${ }^{35}$. The plots in the Figure are multi linear with three distinct regions indicating three different kinetic mechanisms. The initial curved region corresponds to the external surface uptake, the second stage relates the gradual uptake reflecting intraparticle diffusion as the rate limiting step and final plateau region indicates equilibrium uptake. Based on the results it may be concluded that the intraparticle diffusion is not only the rate determining step ${ }^{36}$.

\section{Influence of adsorbent dose}

The effect of adsorbent dose on fluoride removal at fixed initial fluoride concentration of 10 $\mathrm{mg} / \mathrm{L}, \mathrm{pH} 4$, shaking speed $200 \mathrm{rpm}$ and contact time $150 \mathrm{~min}$ is shown in Figure 10. It was observed that percentage removal of fluoride increased from $30 \%$ to $82 \%$ with increase in adsorbent dose from 0.1 to $0.6 \mathrm{~g} / 100 \mathrm{~mL}$ of CCS. This increase in loading capacity is due to the availability of larger number of active adsorption sites. It can also be seen that the fluoride removal markedly increased up to adsorbent dose of $0.6 \mathrm{~g}$ due to increase in adsorbent/fluoride ratio, however, further increase in adsorbent dose does not show any appreciable improvement in fluoride removal. 


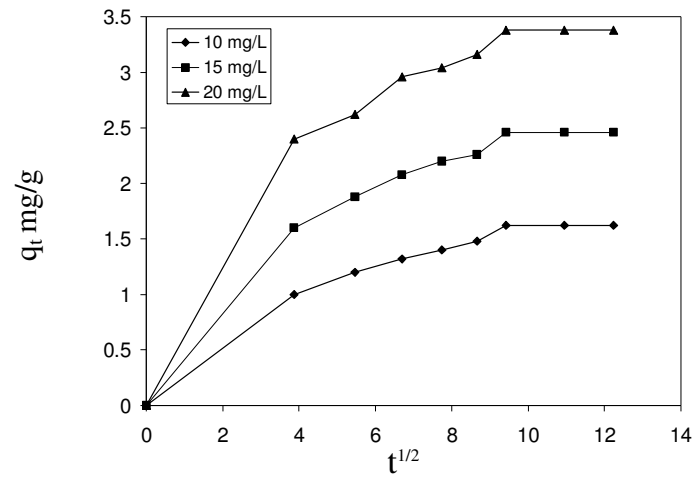

Figure 9. Weber-Morris plots for CCS.

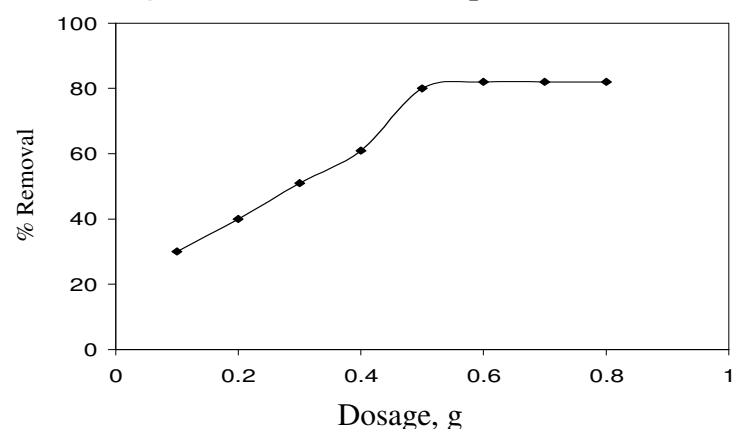

Figure 10. Influence of adsorbent dose on percent removal of fluoride on CCS.

\section{Column studies}

The column adsorption of fluoride from aqueous solution on CCS was investigated and graphically represented in Figure 11. The results of the column experiment were used to obtain breakthrough curves by plotting volume of aqueous solution $(\mathrm{mL})$ versus $\mathrm{C}_{\mathrm{e}} / \mathrm{C}_{\mathrm{i}}$. Breakthrough is attained when the concentration of solute in the effluent is almost equal to influent concentration and remains unchanged. As it can be seen from the Figure 11, the outflow concentration profile shows that fluoride removal is fast and highly effective during the initial phase. Subsequently fluoride removal decreases, as a consequence of the progressive saturation of the binding sites. After passing $540 \mathrm{~mL}$ of fluoride solution for cycle 1 and $500 \mathrm{~mL}$ of fluoride solution for cycles 2 and 3 through the column, the column gets saturated. The breakthrough adsorption capacity $\left(\mathrm{q}_{\mathrm{e}}\right), 1.104,0.896,0.704 \mathrm{mg} / \mathrm{g}$ have been estimated for cycles 1, 2 and 3 respectively. From the Figure 11 it can be concluded that CCS is a good biosorbent of fluoride removal from aqueous medium.

\section{Desorption studies}

Attempts were made to regenerate CCS loaded with fluoride using various solvents like mineral acids, bases and some salt solutions. Among them, $0.1 \mathrm{M} \mathrm{NaOH}$ is chosen as it is found to be effective, non-damaging, non-polluting, and cheap. The CCS exposed to $\mathrm{NaOH}$ remained the same and is suitable for subsequent cycles. After two cycles the original color of the CCS is lost. However, it continued to desorb fluoride to some extent. Figure 12 shows that the elution curves are sharp at the initial stages of cycle 1,2, and 3 and decrease with higher eluant volumes. $\mathrm{NaOH}$ is capable of removing about $91 \%$ of the fluoride adsorbed on the biosorbent. Maximum desorption occurs in 60 minutes with $60 \mathrm{~mL}$ volume of $0.1 \mathrm{~N} \mathrm{NaOH}$. 


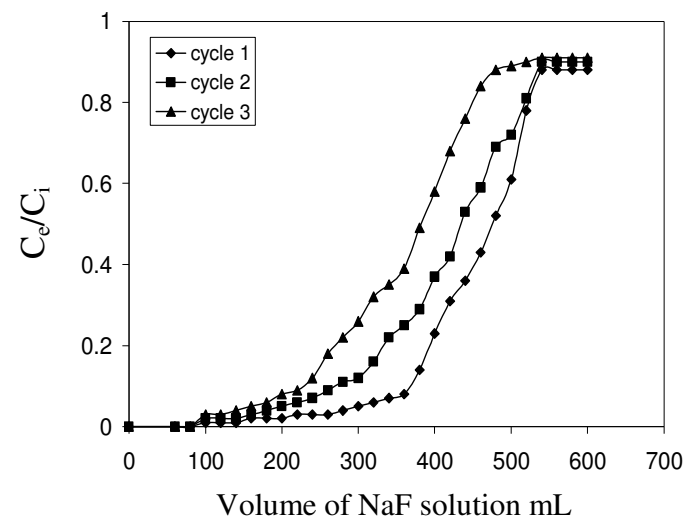

Figure 11. Column breakthrough curves for adsorption of fluoride on CCS.

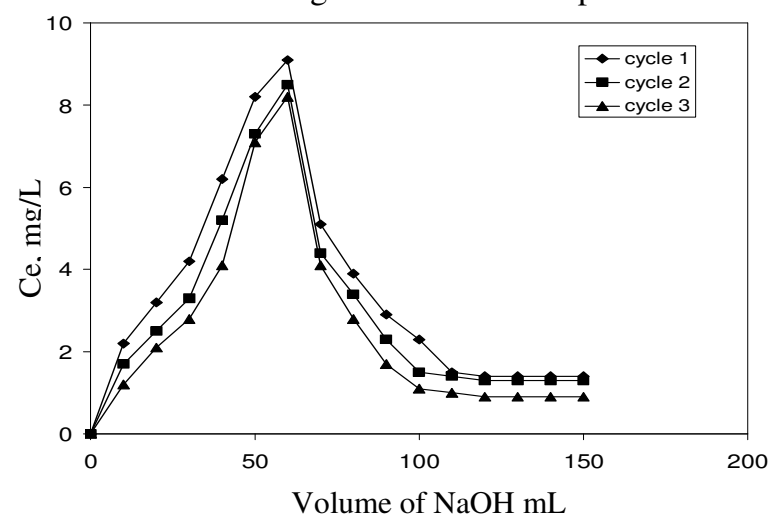

Figure 12. Desorption curves of fluoride adsorbed on CCS.

\section{Conclusions}

CCS is suitable adsorbent for the removal of fluoride from aqueous solution. The removal of fluoride from aqueous solution strongly depends on the contact time, $\mathrm{pH}$ of the solution and amount of adsorbent. The equilibrium data fitted the Langmuir and Freundlich isotherms. Data revealed that fluoride removal on CCS is complex and both the surface adsorption as well as intraparticle diffusion contribute to the rate determining step. The breakthrough curves for adsorption of fluoride from dilute solutions using CCS show the mutual effects of the adsorption capacities and adsorption rate and can explain the dependence of the shape of the breakthrough curves on experimental parameters. The FTIR studies indicate the participation of surface $\mathrm{OH}$ and $\mathrm{NH}_{2}$ groups in the fluoride exchange. The kinetics of adsorption of fluoride on CCS follows Pseudo-second order model. The material is cheap and indigenous. The adsorption method is also very simple, does not cause any pollution, hence eco-friendly. Hence, CCS could be employed as a low cost defluoridating agent.

\section{References}

1. Wang Y and Reardon E J, Appl Geochem., 2001, 16, 531-539.

2. Lounici H, Addour L, Belhocine D, Grib H, Naicolas S and Bariou B, Desalination, 1997, 114, 241-251.

3. Srimurali M, Pragathi A and Karthikeyan J, Environ. Pollut., 1998, 99, 285-289.

4. Hichour M, Persin F, Sandeaux J and Gavach C, Sep Purif Technol., 2000, 18, 1-11. 
5. Amor Z, Malki S, Taky M, Bariou B, Mameri N and Elmidaoui A, Desalination, 1998, 120, 263-271.

6. Hasany S M and Choudhary M H, Appl Radioactive Iso., 1996, 47(4), 467-471.

7. Cohen D and Conrad H M, Desalination, 1998, 117, 19-35.

8. World Health Organization, WHO Chemical fact sheets: Fluoride. Geneva, 2006, Vol. 1, $3^{\text {rd }}$ Ed., 375-377.

9. Hichour M, Persin F, Sandeaux J and Gavach C, Sep Purif Technol., 2000, 18, 1-11.

10. Amor Z, Bariou B, Mameri N, Taky M, Nicolas S and Elmidaoui A, Desalination, 2001, 133, 215-223.

11. Garmes H, Persin F, Sandeaux J, Pourcelly G and Mountadar M, Desalination, 2002, 145, 287-291.

12. Mjengera H and Mkongo G, Phys Chem Earth, 2003, 28, 1097-1104.

13. Ghorai S and Pant K K, Chem Eng J., 2004, 98, 165-173.

14. Abe I, Iwasaki S, Tokimoto T, Kawasaki N, Nakamura T and Tanada S, J Colloid Interface Sci., 2004, 275, 35-39.

15. Srimurali M, Pragathi A and Karthikeyan J, Environ Pollut., 1998, 99, 285-289.

16. Cengiloglu Y, Kir E and Ersoz M, Sep Purif Technol., 2002, 28, 81-86.

17. Agarwal M, Rai K, Shrivastav R and Dass S, J Cleaner Production, 2003, 11, 439-444.

18. Wasay S A, Haron M J and Tokunaga S, Water Environ Res., 1996, 68, 295-300.

19. Liang L V, Jing H, Min W, Evans D G and Xue D, J Hazar Mater.(B), 2006, 133, 119-128.

20. Diaz-Nava C, Olguin M T and Solache-Rios M, Sep Sci Technol., 2002, 37, 3109-3128.

21. Meenakshi S, Pius A, Karthikeyan G and Appa Rao B V, Indian J Environ Prot., 1991, 11, 511-513.

22. Karthikeyan G, Shammuga Sundarraj A, Meenakshi S and Elango K P, J Indian Chem Soc., 2004, 81, 461-466.

23. Langmuir I, J Am Chem Soc., 1916, 38, 2221-2295.

24. Freundlich H F M, Z Pys Chem., 1906, 57, 385-470.

25. Wei M, Fei-Qun Y, Han M and Wang R, J Hazard Mater., 2007, 143, 296-302.

26. Kamble S P, Jagtap S, Labhsetwar N K, Thakare D and Rayalu S S, Chem Eng J., 2007, 129, 173-180.

27. Menkouchi Sahli M A, Annouar S, Tahaikt M, Mountadar M and Soufiane A, Desailination, 2007, 212, 37-45.

28. Das N, Pattanaik P and Das R, J Colloid Interface Sci., 2005, 292, 1-10.

29. Sujana M C, Thakur R S and Rao S B, J Colloid Interface Sci., 1988, 206, 94-101.

30. Quek S Y, Wase D A J and Forster C F, Water SA, 1998, 24(3), 251-256.

31. McKay G and Ho Y S, Water Res., 1999, 33(2), 578-584.

32. Chiou M S and Li H Y, J Hazard Mater., 2002, 93(2), 233-248.

33. Sag Y and Aytay Y, Biochem Eng J., 2002, 12, 143-153.

34. Weber W J and Morris J C, J Sanitary Eng Div., 1964, 90, 79-107.

35. Ozcan A and Ozcan A S, J Hazard Mater., 2005, 125, 252-259.

36. Yadav A K, Kaushih C P, Haritash A K, Kansal A and Rani N, J Hazard Mater., 2005, 128, 289-293. 


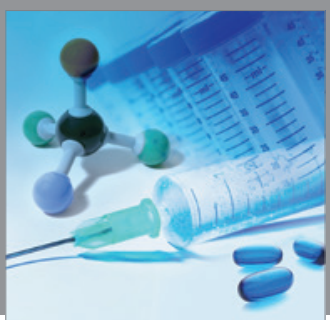

International Journal of

Medicinal Chemistry

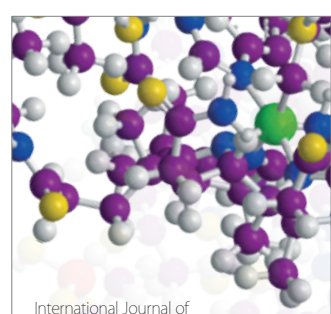

Carbohydrate Chemistry

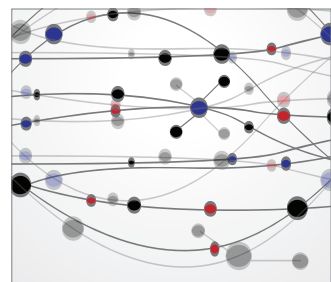

The Scientific World Journal
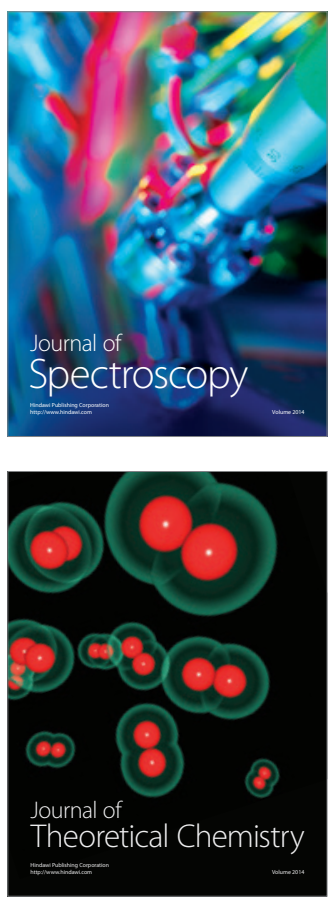
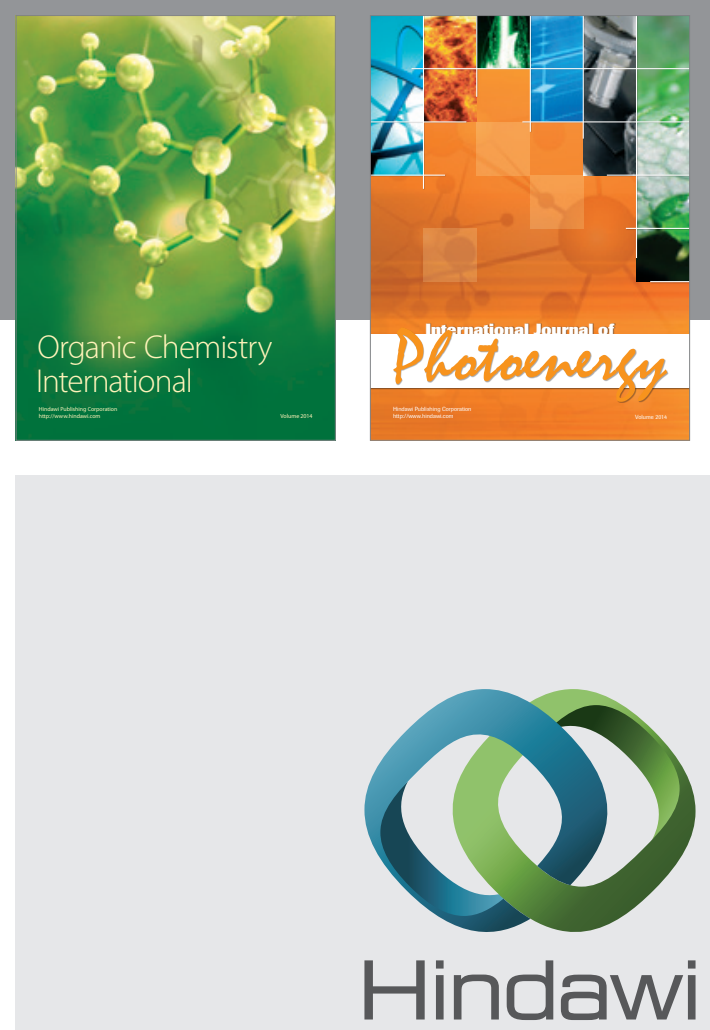

Submit your manuscripts at

http://www.hindawi.com
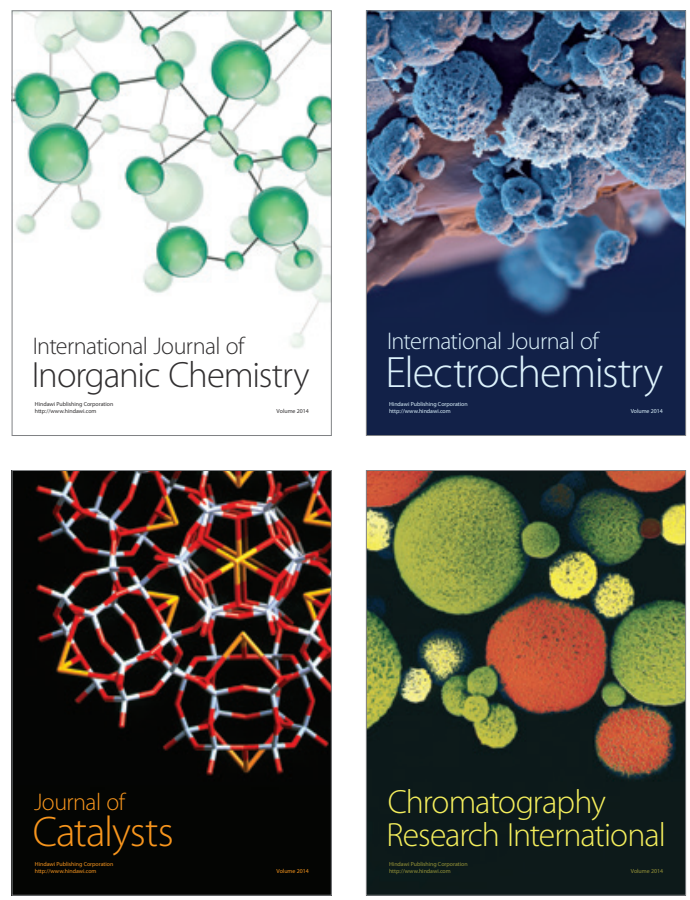
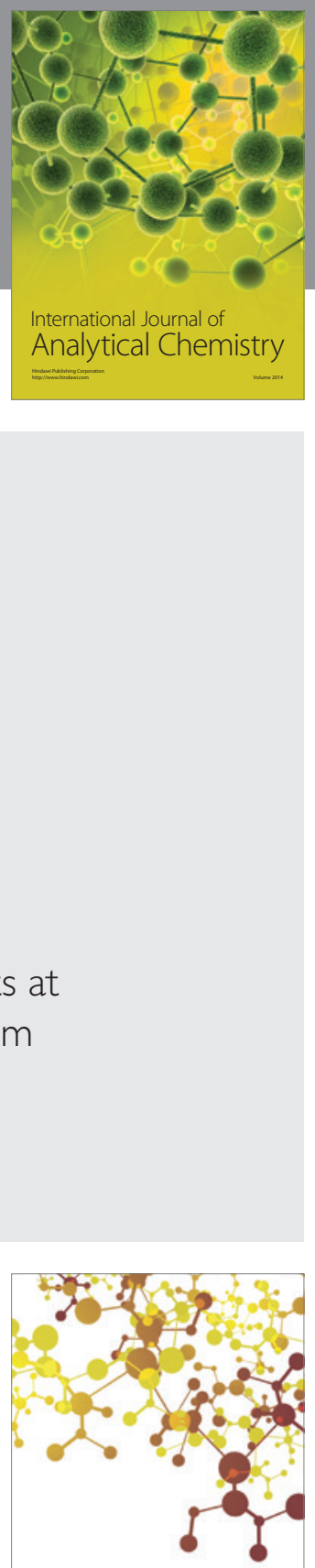

Journal of

Applied Chemistry
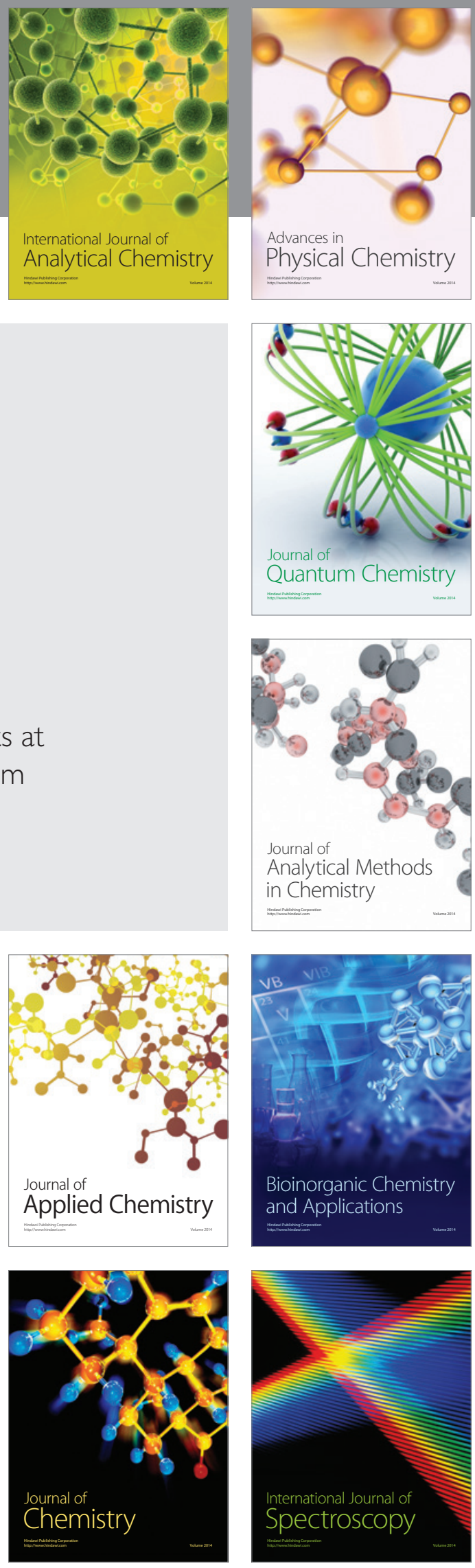